\title{
DEVELOPMENT OF A MODIFIED CARBON ELECTRODE WITH IONIC LIQUID AND ITS APPLICATION FOR ELECTROCATALYTIC OXIDATION AND VOLTAMMETRIC DETERMINATION OF LEVODOPA
}

\author{
V. MONCADA, A. ÁLVAREZ-LUEJE* \\ Chemical and Pharmaceutical Sciences Faculty, University of Chile, PO Box 233, Santiago 1, Chile
}

Dedicated to my friend Luis

\begin{abstract}
A carbon paste electrode was modified with the ionic liquid 1-butyl-4-methylpyridinium hexafluoro phosphate and applied for the study of the electrocatalytic oxidation and voltammetric determination of the drug levodopa. The developed modified electrode was characterized using cyclic voltammetry and scanning electron microscopy. The oxidation of levodopa at the surface of a modified electrode occurs at lower potentials than that of an unmodified carbon paste electrode and both an enhancement of the anodic peak current and a signal narrower and better defined with the modified electrode were observed. Accordingly, a method for the determination of levodopa was developed using differential pulse voltammetry, at $\mathrm{pH} 4$ and with an accumulation time of 4 min. The oxidation of levodopa exhibited a dynamic range between $2.4-16.6 \mu \mathrm{g} / \mathrm{mL}$ and detection and quantitation limits of $0.63 \mathrm{and} 1.4 \mu \mathrm{g} / \mathrm{mL}$, respectively. The method was applied to the determination of levodopa in capsules.
\end{abstract}

Keywords: Levodopa, carbon paste, ionic liquid, modified electrodes, Voltammetry.

\section{INTRODUCTION}

Levodopa, 3-(3,4-dihydroxyphenyl)-1-alanine (Figure 1), is the immediate precursor of the neurotransmitter dopamine and is the drug of choice for the treatment of Parkinson's disease. Levodopa is rapidly decarboxylated by peripheral enzymes so that very little parent drug is available to penetrate into central nervous system to generate dopamine. Consequently, levodopa is usually given with a peripheral dopa-decarboxylase inhibitor such as benserazide or carbidopa to increase the amount of levodopa that can enter the brain. Levodopa is fast absorbed from the gastrointestinal tract and peak plasma concentrations are reached within 2 hours of oral doses. It is quickly decarboxylated, mostly in the gut, liver and kidney, to dopamine, which is metabolised in turn, mainly to dihydroxyphenylacetic acid and homovanillic acid. Metabolism also include O-methylation, transamination and oxidation, producing others minor metabolites as noradrenaline and 3-O-methyldopa. About $80 \%$ of an oral dose of levodopa is excreted in the urine within 24 hours mainly as dihydroxyphenylacetic and homovanillic acids. ${ }^{1,2}$

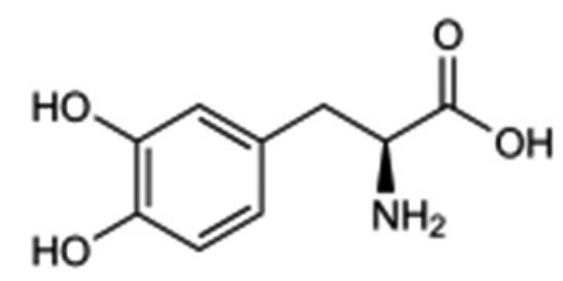

Figure 1. Chemical structure of levodopa.

Numerous methods have been used for the determination of levodopa in matrices such as in raw material, pharmaceutical formulations and biological fluids, including spectrophotometry, liquid chromatography, capillary zone electrophoresis and electrochemistry. ${ }^{3-8}$

The electrochemistry of the oxidation of levodopa has been described using different electrodes, including carbon, platinum or gold electrodes. This has enabled the electrochemical characterization and determination of levodopa. ${ }^{9-14}$

Also, the electrocatalytic oxidation and voltammetric determination of levodopa in the presence of carbidopa at the surface of a nanostructure based electrochemical sensor has been carried out. ${ }^{15}$

Ionic liquids (IL) had been widely used in the fields of electrochemistry and electroanalysis, and have been used for the preparation of the modified electrodes due to the good ionic conductivity and wide electrochemical windows. Due to better conductivity of IL compared with paraffin oil, they are appropriate for the preparation of carbon paste electrodes (CPE) in voltammetric measurements, because they reduce the charging current and consequently improved sensitivity and detection limit. ${ }^{16-18}$

Recently, the electrochemical oxidation of levodopa on the surface of a carbon paste electrode modified with graphene nanosheets, 1-(4-bromobenzyl)4-ferrocenyl-1H-[1,2,3]-triazole and the hydrophilic IL n-hexyl-3-methylimidazolium hexafluoro phosphate as a binder was studied. ${ }^{19}$

According to the above, in the present work we produce and characterized CPE modified with the IL 1-butyl-4-methylpyridinium hexafluorophosphate to be applied to the study of the electrochemical behaviour of levodopa and to develop a different pulse voltammetric method to determine this drug in dosage form.

\section{EXPERIMENTAL}

\section{Apparatus}

Cyclic voltammetry (CV) and differential pulse voltammetry (DPV) experiments were performed using a multichannel $\mathrm{CHI} 1030 \mathrm{~A}$ potentiostat (CH Instruments, Inc., Austin, USA) controlled by a computer with 1030B CHI software. A 3-electrode system was used containing a CPE or a modified CPE $(\Phi=3.5 \mathrm{~mm})$ as the working electrode, a Pt wire as the counter electrode and an $\mathrm{Ag} / \mathrm{AgCl}$ electrode as the reference. Scanning electron microscopy (SEM) was performed on a Jeol JSM-5410 SEM (Tokyo, Japan). All experiments were performed at room temperature.

HPLC measurements were carried out by using a Jasco assembly equipped with a controller pump (PU-2089S), a column oven (CO-2060) and a photodiode array detector (MD-2018). The data acquisition was performed by ChromNav software. Chromatography was performed on a Phenomenex Luna C8 analytical column $(4.6 \mathrm{~mm} \times 150 \mathrm{~mm}, 5 \mu \mathrm{m})$ at $25^{\circ} \mathrm{C}$, a $20 \mu \mathrm{L}$ injection loop (Rheodyne valve) and a UV detector set at $220 \mathrm{~nm}$.

Chemicals and solutions

Graphite powder(FisherChemAlert),Levodopa (99.3\%,Chile Laboratories, Santiago, Chile), 1-Butyl-4-methylpyridinium hexafluorophosphate $(>97.0 \%$, Aldrich), ferrocene-methanol, potassium ferricyanide and hexaammineruthenium(III) chloride from Sigma, mineral oil (IR spectroscopy grade, Sigma-Aldrich). Potassium dihydrogen orthophosphate, sodium decanesulphonate, orthophosphoric acid and acetonitrile HPLC grade were obtained from Merck. All other reagents used were of pro-analysis quality and all solutions were prepared with water obtained from a Milli-Q ultra-pure water purification system.

Preparation of the solutions

Buffer solutions. A $0.1 \mathrm{M}$ Britton-Robinson buffer (an acetic, boric and phosphoric acid mixture) was used. The desired $\mathrm{pH}$ was obtained by the addition of concentrated $\mathrm{NaOH}$ or $\mathrm{HCl}$ solutions.

Stock drug solutions. Standard stock solution of levodopa were prepared daily at a constant concentration of $1 \times 10^{-2} \mathrm{M}$ in $0.1 \mathrm{M}$ Britton-Robinson buffer (BRB). This solution was protected from light working in amber glass material.

Work solutions. Stock standard solution of levodopa was diluted with 0.1 $\mathrm{M} B \mathrm{BRB}$ to prepare working solutions of concentrations ranging from $1 \times 10^{-4} \mathrm{M}$ 
to $1 \times 10^{-3} \mathrm{M}$. The $\mathrm{pH}$ was adjusted with small aliquots of concentrated $\mathrm{NaOH}$ or $\mathrm{HCl}$.

Construction of carbon paste electrode (CPE) and modified CPE with ionic liquid (IL-CPE).

Carbon paste (CP) was prepared by hand-mixing paraffin oil and graphite powder with a ratio of $95 / 5$ graphite/paraffin oil (w/w). The IL-CPE was fabricated by a similar procedure by adding different percentages of IL (w/w) to $\mathrm{CP}$. The paste was packed into the cavity of a Teflon tube $(3.5 \mathrm{~mm}$ diameter). An electrical contact was established via a copper wire inserted through the opposite end. Prior to use, a mirror-like surface was obtained by smoothing the electrode on a weighing paper.

\section{Analytical procedure}

Calibration curve preparation. Working solutions ranging from 2 to 17 $\mu \mathrm{g} / \mathrm{mL}$ were prepared by diluting the levodopa stock solution with $0.1 \mathrm{M}$ BRB.

Assay procedure. Twenty commercial capsules of benserazide (Prolopa ${ }^{\circledR}$ HBS, Roche, amount declared per capsule $25 \mathrm{mg}$ benserazide and $100 \mathrm{mg}$ levodopa) were weighed and mixed. A quantity of powder containing the equivalent of $10 \mathrm{mg}$ levodopa was suspended in $20 \mathrm{~mL}$ of $0.1 \mathrm{M}$ BRB solution $\mathrm{pH} 4$ with ultrasonic agitation and diluted to a final volume of $100 \mathrm{~mL}$ with the same solvent. Then, $1 \mathrm{~mL}$ of this solution was further diluted to $10 \mathrm{~mL}$ with $0.1 \mathrm{M}$ BRB solution $\mathrm{pH}$ 4. Finally, the sample solution was transferred to a voltammetric cell and recorded at least twice from 100 to $500 \mathrm{mV}$. The amount of levodopa $(\mathrm{mg})$ in the sample solution was calculated using the calibration curve.

\section{RESULTS AND DISCUSSION}

The electrochemical behaviors of CPE modified with different percentages of IL were characterized using the redox mediators ferrocenemethanol, potassium ferricyanide and hexaammineruthenium(III) chloride. In Figure 2, cyclic voltammograms of each mediator using modified CPE with different percentages of IL are shown. As can be seen in Figure 2, peak current increases as the percentage of IL increases for all the mediators assayed, mainly for ferricyanide and hexaammineruthenium. Thus, the redox response of the tested mediators seem to be influenced by interactions of $\pi-\pi$ type between analyte (ferrocenemethanol) and the IL, rather than an effect of charge between them, because there not are great differences in the response of the hexamin ruthenium and ferricyanide to the IL tested, except for ferricyanide which has shown an improvement in the reaction reversibility, with $\Delta$ Epa-Epc $=139 \mathrm{mV}$ vs. $\triangle \mathrm{Epa}-\mathrm{Epc}=90 \mathrm{mV}$ for EPC and IL-CPE, respectively, indicating that the electrochemical process occurs with a faster electron transfer rate on IL-CPE.
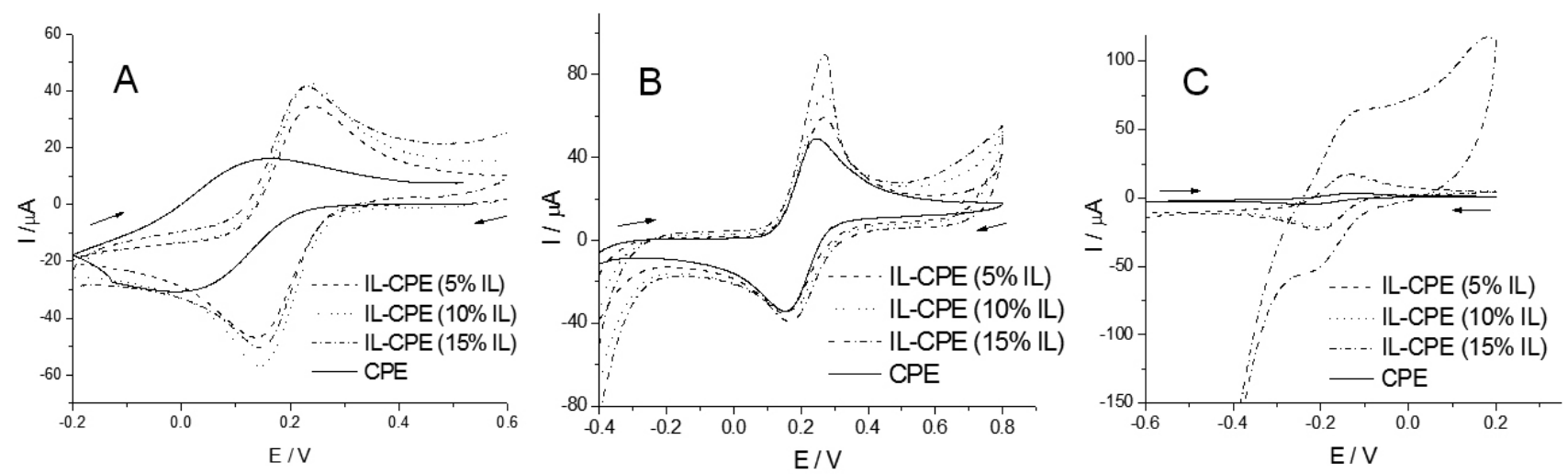

Figure 2. Cyclic voltammograms of the different electrodes in a Britton-Robinson buffer solution ( $\mathrm{pH}$ 7.4) containing potassium ferricyanide (A), ferrocenemethanol (B) and hexaammineruthenium (III) chloride (C). Scan rate: $100 \mathrm{mV} / \mathrm{s}$.

The CPE and IL-CPE were also characterized by cyclic voltammetry in $0.1 \mathrm{M}$ Britton-Robinson buffer $\mathrm{pH}$ 7.4, determining the capacitance values as reflect of the electroactive area of each electrode. A high background response was obtained on the IL-CPE due to the high capacitance of the IL: $4.24 \mu \mathrm{F}$ for IL-CPE vs. $0.124 \mu \mathrm{F}$ for CPE. The results were in agreement with previous research about the IL-modified electrodes. ${ }^{20-23}$

The electrochemically effective surface areas of the CPE and IL-CPE were calculated using a chronocoulometric method with a $0.1 \mathrm{M}$ potassium ferricyanide solution $(1 \mathrm{mM} \mathrm{KCl})$, according to the Anson equation: ${ }^{24}$

$$
Q(t)=\frac{2 n F A C D^{\frac{1}{2}} t^{\frac{1}{2}}}{\pi^{\frac{1}{2}}}+Q_{d l}+Q_{a d s}
$$

where $\mathrm{A}$ is the surface area of the working electrode, $\mathrm{C}$ is the concentration of the substrate, $\mathrm{D}$ is the diffusion coefficient $\left(7.6 \times 10^{-6} \mathrm{~cm}^{2} \mathrm{~s}^{-1}\right)^{25}, \mathrm{Q}_{d l}$ is the double-layer charge which could be eliminated via background subtraction, and $\mathrm{Q}$ is the Faradaic charge. Based on the slope of the linear relationship between $\mathrm{Q}$ and $\mathrm{t}^{1 / 2}$, the A values for the CPE and IL-CPE were calculated to be $0.04 \mathrm{~cm}^{2}$ and $0.12 \mathrm{~cm}^{2}$, respectively. These results show that the electrode's effective surface area in IL-CPE increased 3 fold after modification, increasing the current response and diminishing the detection limit.

The morphological features of the two electrodes were studies using SEM. The CP is characterized by a surface formed by irregularly shaped flakes of graphite and each layer is clearly distinguished (Figure 3A). Figure 3B shows a SEM image of IL-CP with a less uniform surface topography and a slight increase in roughness and particle agglomeration of a smaller size.
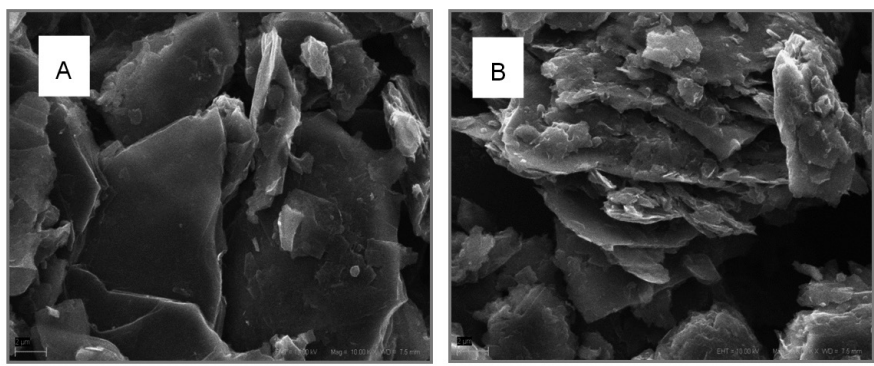

Figure 3. SEM images of the carbon paste (A), IL-CP (B). Accelerating voltage: $10 \mathrm{keV}$, magnification: $500 \times$.

Electrochemical behavior of levodopa

Levodopa posses a catechol group and can undergoes a two-electron oxidation to give the corresponding quinone derivative, as has been widely described ${ }^{26-28}$

The drug exhibits a well-defined anodic signal on the IL-CPE between the $\mathrm{pH}$ ranges $1.5-6$ (Figure 4). 


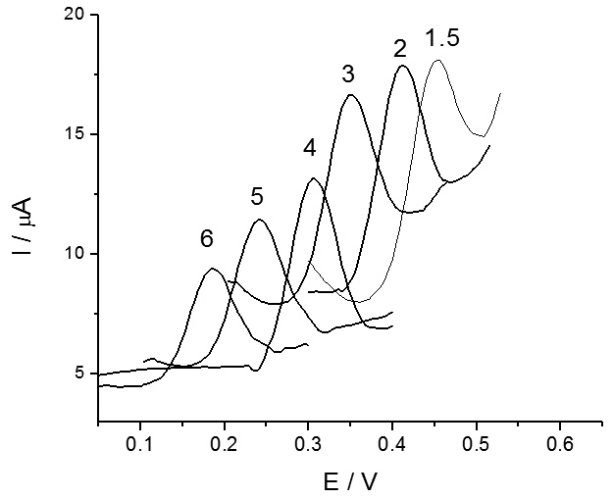

Figure 4. DPVs of a $1 \times 10^{-4} \mathrm{M}$ levodopa solution at different $\mathrm{pHs}$ in $0.1 \mathrm{M}$ Britton-Robinson buffer.

This signal shows a $\mathrm{pH}-$ dependent behavior and is shifted toward lower anodic potentials as the $\mathrm{pH}$ increases, facilitating the oxidation process. The Ep-pH plot exhibits a linear dependence with slope of $58 \mathrm{mV} / \mathrm{pH}\left(\mathrm{r}^{2}=0.995\right)$. On the contrary, peak current decreases as the $\mathrm{pH}$ increases with a maximum at $\mathrm{pH} 2$ (Figure 5). The electrocatalytic effect of IL on levodopa oxidation is shown in Figure 6, in which the peak potential of levodopa oxidation at the surface of IL-CPE shifts by about $40 \mathrm{mV}$ toward negative values compared with that at the CPE ( $420 \mathrm{mV}$ vs. $460 \mathrm{mV}$, respectively). In addition, both an enhancement of the anodic peak current and a signal narrower and better defined were observed.
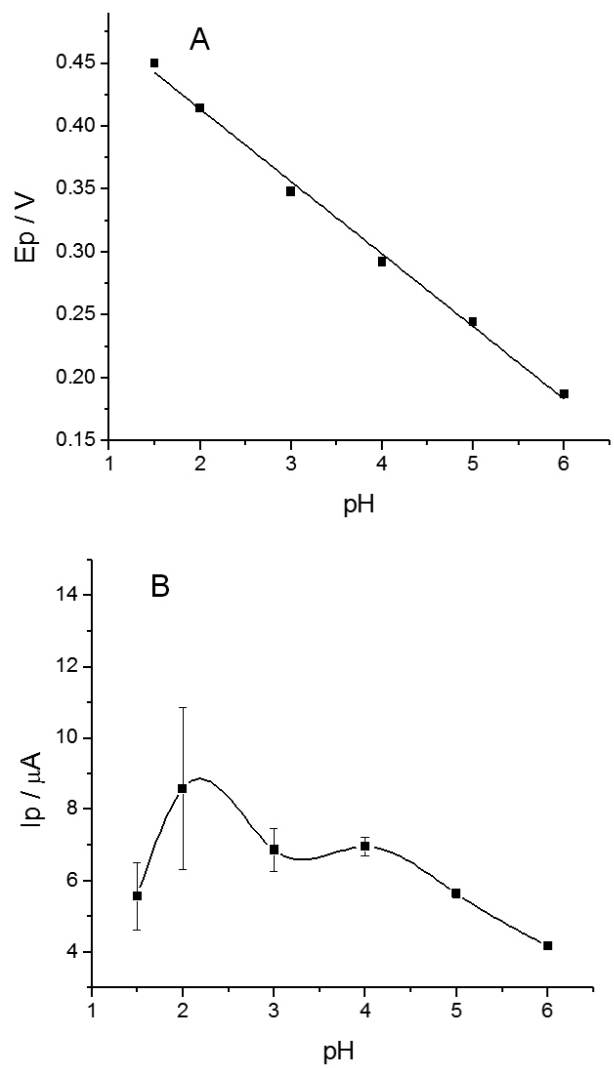

Figure 5. (A) Peak potential evolution of a $1 \times 10^{-4} \mathrm{M}$ levodopa solution at different pHs in 0.1 M Britton-Robinson buffer and (B) a peak current (Ip) vs. $\mathrm{pH}$ graph.

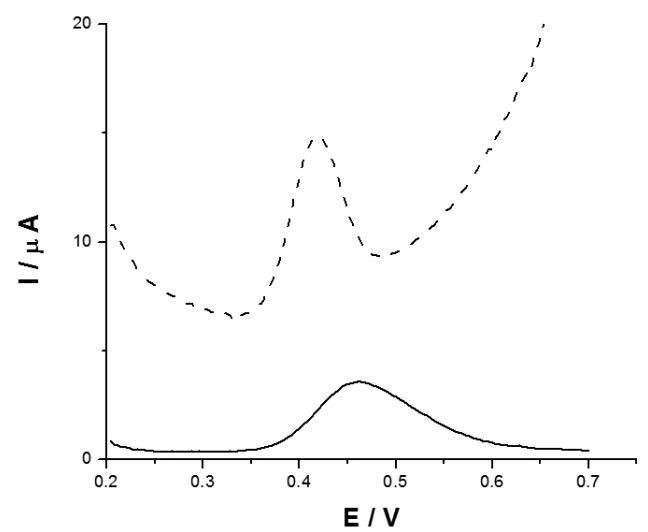

Figure 6. DPVs of a $1 \times 10^{-4} \mathrm{M}$ levodopa solution with CPE (solid line) and IL-CPE (dashed line), 4 min accumulation time, $\mathrm{pH} 2$.

To optimize the experimental conditions for determining levodopa, the effect of accumulation time and the ionic strength of the supporting electrolyte were evaluated. First, as can be seen in Figure $5 \mathrm{~B}$, at $\mathrm{pH} 2$ the maximum peak current values were obtained, but was not selected to further analytical studies due to the response is little reproducible. Consequently, to get a better reproducibility but sacrificing some the sensitivity, $\mathrm{pH} 4$ was selected. On the other hand, no effect of ionic strength on the oxidation peak of levodopa was observed in the range of 0.05-0.2 M Britton-Robinson buffer, and consequently for further analytical studies 0.1 M Britton-Robinson buffer was selected.

Figure 7A shows the effect of accumulation on the levodopa peak current. As can be seen, the solution required stirring for 4 min to achieve a maximum peak current, after which the current reaches a plateau, indicating that the electrode is saturated. Thus, in the selected analytical conditions, the levodopa signal is increased by about 2 -fold and shows a better definition as compared with the unmodified electrode (Figure 7B). In addition, the catalytic effect of IL permits that levodopa oxidize at lower potentials at the IL-CPE compared with CPE (0.296 V vs. $0.332 \mathrm{~V}$, respectively)
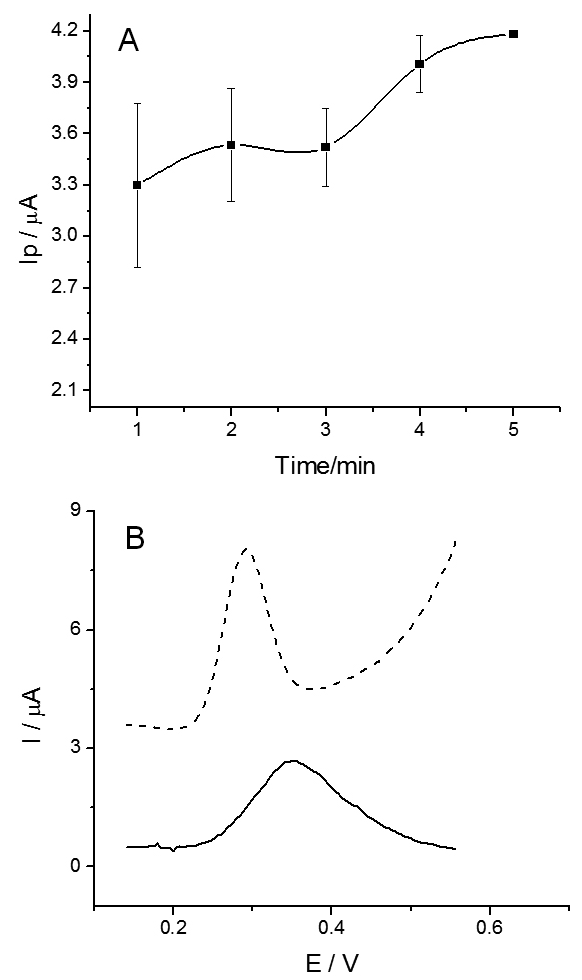

Figure 7. (A) Peak current evolution with time accumulation (500 rpm) for $1 \times 10^{-4} \mathrm{M}$ levodopa at $\mathrm{pH} 4$. (B) DPVs of a $1 \times 10^{-4} \mathrm{M}$ levodopa solution with $\mathrm{CPE}$ (solid line) and IL-CPE (dashed line), 4 min accumulation time, $\mathrm{pH} 4$. 
Under the optimized conditions ( $\mathrm{pH} 4$, with stirring for an accumulation time of $4 \mathrm{~min}$ ), a linear response for methyldopa concentrations between 2.4 $16.6 \mu \mathrm{g} / \mathrm{mL}$ was obtained. Figure 8 provides both the DPVs and the calibration curve of the levodopa.

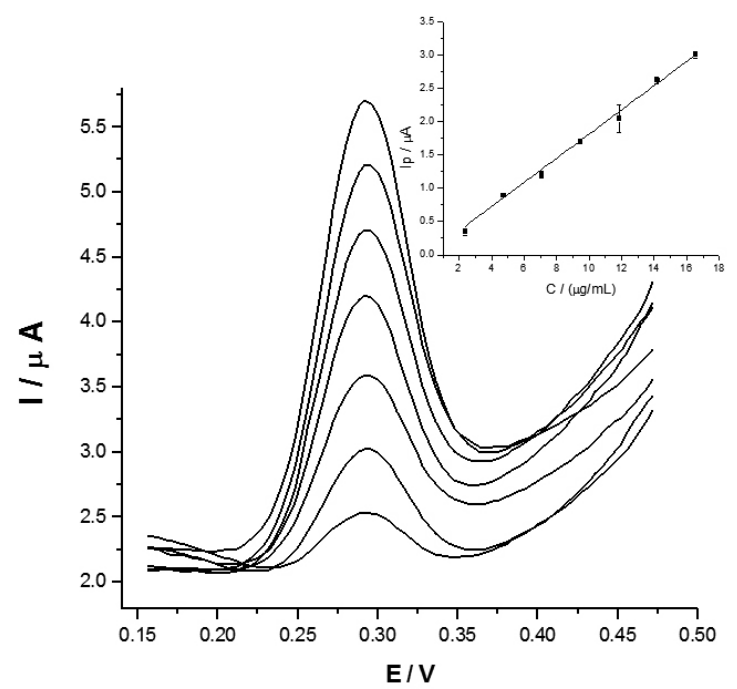

Figure 8. DPVs of the levodopa calibration curve $(2.4-16.6 \mu \mathrm{g} / \mathrm{mL}$, $0.1 \mathrm{M}$ Britton-Robinson buffer solution, $\mathrm{pH} 4$ ). Inset: linear calibration curve (peak current $v s$. levodopa concentration).

The detection (LOD) and quantitation limits (LOQ) of the method were calculated using the average $\left(\mathrm{Y}_{\mathrm{b}}\right)$ and standard deviations $\left(\mathrm{S}_{\mathrm{b}}\right)$ of the blank estimated response, the slopes of the calibration curve $(\mathrm{m})$ and signal/noise ratios of 3 and 10 according to the following expressions: ${ }^{29}$

$$
L O D=\frac{Y_{b}+3 \sigma_{b}}{m} \quad L O Q=\frac{Y_{b}+10 \sigma_{b}}{m}
$$

The within-day and inter-day reproducibilities of the five independent electrodes were considered adequate with coefficients of variation below $5.5 \%$. Table 1 summarizes the analytical parameters, highlighting the low LOD and LOQ achieved. The as-obtained LOD is on the order of than those reported for some modified electrodes used in the electrocatalysis of levodopa, for example $0.17 \mu \mathrm{g} / \mathrm{mL}$ for a basal plane pyrolytic graphite electrode modified with chloro(pyridine) bis-(dimethylglyoximato)cobalt-(III)6, 0.01-0.05 $\mu \mathrm{g} / \mathrm{mL}$ for modified glassy carbon and CPE. . $7,30.31_{13} 13 \mu \mathrm{g} / \mathrm{mL}$ in a gold screen-printed electrode. ${ }^{14}$

Finally, the developed DPV method was applied successfully to the assay of levodopa in presence of benserazide in capsules. For comparative purposes, also HPLC assay was carried out as is the official method of British Pharmacopoeia ${ }^{32}$. The results for the assay of levodopa were found to be 93.8 $\% \pm 1.9 \%$ over declared amount for DPV and $96.1 \% \pm 2.2 \%$ over declared amount for HPLC, and no interference of both excipients and benserazide was detected.

Table 1. Analytical parameters for the DPV method for levodopa quantitation using an IL-CPE.

\begin{tabular}{|l|l|}
\hline Parameter & DPV $(\mathrm{E}=0.296 \mathrm{~V})$ \\
\hline Within-day reproducibility, CV $(\%)$ & 3.5 \\
\hline Inter-day reproducibility, CV $(\%)$ & 5.4 \\
\hline Calibration curve $(\mathrm{Ip}, \mu \mathrm{A} ; \mathrm{C}, \mu \mathrm{g} / \mathrm{mL})$ & $\begin{array}{l}\mathrm{Ip}=0.182 \times \mathrm{C}+0.00149 \\
\mathrm{r}^{2}=0.995(\mathrm{n}=7)\end{array}$ \\
\hline Concentration range $(\mu \mathrm{g} / \mathrm{mL})$ & $2.4-16.6$ \\
\hline Detection limit $(\mu \mathrm{g} / \mathrm{mL})$ & 0.63 \\
\hline Quantitation limit $(\mu \mathrm{g} / \mathrm{mL})$ & 1.4 \\
\hline
\end{tabular}

\section{CONCLUSIONS}

A stable, sensitive and reproducible CPE modified with the IL 1-butyl4-methylpyridinium hexafluorophosphate was developed. This electrode proved an effective electrocatalyst for determining levodopa compared with an unmodified CPE. From an analytical point of view, the use of the CPE modified with the IL allows the development of a DPV method with a low LOD and LOQ and good reproducibility. The simplicity of the sample treatment required for this voltammetric method allowed the quantification of levodopa in capsules.

\section{ACKNOWLEDGEMENTS}

The authors are grateful for the support of FONDECYT Grant No. 1110182

\section{REFERENCES}

1. S.C. Sweetman (Ed.), Martindale: The Complete Drug Reference, Pharmaceutical Press, London, 2007 (Electronic version).

2. A. Moffat, M. Osselton, B. Widdop, Clarke's Analysis of Drugs and Poisons. Pharmaceutical Press. Electronic version, third edition, 2004.

3. M. Chamsaza, A. Safavia, J. Fadaeea, Anal. Chim. Acta 603, 140, (2007)

4. W.H. Kim, M.M. Karim, S.H. Lee, Anal. Chim. Acta 619, 2, (2008)

5. S. Shahrokhian, E. Asadian, J. Electroanal. Chem. 636, 40 (2009)

6. F. R. Figueirêdo Leite, C. M. Maroneze, A. B. Oliveira, W. T. P. d. Santos, F. S. Damos, R. C. S. Luz, Bioelectrochemistry 86, 22, (2012)

7. A. Abbaspour, E. Dehghani, A. Noori, Electroanalysis 23, 2878, (2011)

8. C. Zapata-Urzúa, M. Pérez-Ortiz, M. Bravo, A.C. Olivieri, A. ÁlvarezLueje, Talanta 82, 962, (2010)

9. X. Liu, Z. Zhang, G. Cheng, S. Dong, Electroanalysis 15, 103, (2003)

10. M. Teixeira, M. Bergamini, C. Marques, N. Bocchi, Talanta 63, 1083, (2004)

11. A. Sivanesan, S.A. John, Biosens, Bioelectron. 23, 708, (2007)

12. S. Viswanathan, W.C. Liao, C.C. Huang, W.L. Hsu, A.H. Ja-an, Talanta 74, 229, (2007)

13. Y. Tu, Q. Xu, Q.J. Zou, Z.H. Yin, Y.Y. Sun, Y.D. Zhao, Anal. Sci. 23, $1321,(2007)$

14. M.F. Bergamini, A.L. Santos, N.R. Stradiotto, M.V.B. Zanoni, J. Pharm. Biomed. Anal. 39, 54. (2005)

15. M. Mazloum-Ardakani, Z. Taleat, A. Khoshroo, H. Beitollahi, H. Dehghani, Biosens. Bioelectron. 35, 75, (2012)

16. A. Afkhami, H. Bagheri, A. Shirzadmehr, H. Khoshsafar, P. Hashemi, Electroanalysis 24, 2176, (2012)

17. X. Yu, Y. Chen, L. Chang, L. Zhou, F. Tang, X. Wu, Sens. Actuators B 186, 648, (2013)

18. W. Sun, Y. Wang, Y. Zhang, X. Ju, G. Li, Z. Sun, Anal. Chim. Acta 751, 59, (2012)

19. S. Tajik, M.A. Taher, H. Beitollahi, Electroanalysis 26, 796-806, (2014)

20. E. Rozniecka, G. Shul, J. Sirieix-Plenet, L. Gaillon, M. Opallo, Electrochem. Commun. 7, 299, (2005)

21. J. Zheng, Y. Zhang, P. Yang, Talanta 73, 920, (2007)

22. W. Sun, M. Yang, Y. Li, Q. Jiang, S. Liu, K. Jiao, J. Pharm. Biomed. Anal. 48, 1326, (2008)

23. W. Sun, Q. Jiang, Y. Wang, K. Jiao, Sens. Actuators B 136, 419, (2009)

24. F. Anson, Anal. Chem. 36, 932, (1964)

25. R. Adams, Electrochemistry at Solid Electrodes, Marcel Dekker, New York 1969.

26. S. Viswanathan, W.C. Liao, C.C. Huang, W.L. Hsu, A.H. Ja-an, Talanta 74, 229, (2007)

27. S.M.Wabaidur, S.M. Alam, M.A. Khan, Appl. Chem. 12, 85, (2008)

28. B. Pérez-Mella, A. Álvarez-Lueje, Electroanalysis, 25, 2193, (2013)

29. O.A. Quattrochi, S.A. De Andrizzi, R.F. Laba, Introducción a la HPLC, Aplicación y Práctica, Artes Gráficas Farro, SA, Argentina, 1992.

30. M. Mazloum-Ardakani, H. Beitollahi, M. A. Sheikh-Mohseni, H. Naeimi, J. Iran. Chem. Soc. 9, 27, (2012)

31. X. X. Yan, D.W. Pang, Z. X. Lu, J. Q. Lu, H. Tong, J. Electroanal. Chem. 569, 47, (2004)

32. British Pharmacopoeia. 2003. Co-Beneldopa Capsules. London: Stationery Office, CD room. 